DOI: $10.7242 / 2658-705 X / 2019.2 .3$

УДК 547.592 .13

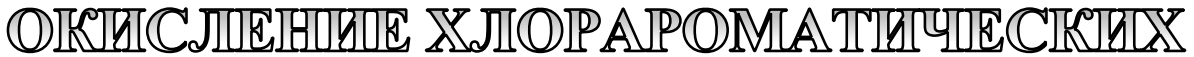

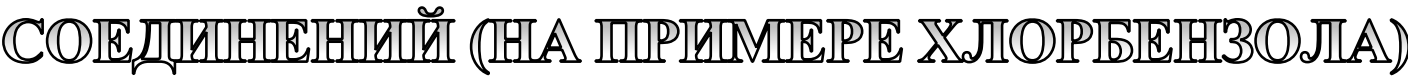

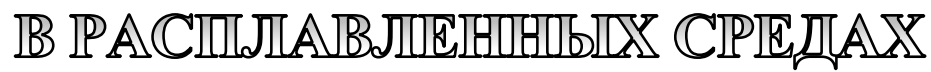

\author{
Т.А. Роздяловская, Институт технической химии УрО РАН
}

Исследована реакция глубокого окисления хлорбензола в расплавленных смесях гидроксидов, карбонатов и хлоридов щелочных и щелочноземельных металлов с добавкой и без активных компонентов: $\mathrm{V}_{2} \mathrm{O}_{5}$ и $\mathrm{Sb}_{2} \mathrm{O}_{5}$ в зависимости от температуры, нагрузки на катализатор, мольного отношения газа окислителя (воздушная смесь) к хлорбензолу. Термическое разложение хлорбензола протекает с низкой степенью превращения, сопровождается значительным коксообразованием. Показано, что среди изученных каталитических систем наибольшую активность в реакции глубокого окисления хлорбензола проявляют расплавленные катализаторы на основе эвтектической смеси хлоридов натрия и кальция с содержанием 20 мас. $\% \mathrm{~V}_{2} \mathrm{O}_{5}$. Процесс коксообразования в меньшей степени наблюдается для каталитической системы $\mathrm{NaOH}-\mathrm{KOH}+10$ мас.\% $\mathrm{V}_{2} \mathrm{O}_{5}$ (эвт.). Образующиеся при окислении хлорароматических соединений хлорид-ионы под действием оксидов переходных металлов окисляются с образованием молекулярного хлора, что продлевает срок службы данных каталитических систем.

Ключевые слова: глубокое окисление, уничтожение отходов, хлорбензол, расплавленные катализаторы, оксиды переходных металлов.

Ароматические хлорпроизводные важные продукты промышленного синтеза, применяющиеся для разнообразных целей. Некоторые из них являются ценными растворителями, обладают инсектицидными свойствами, используются для производства пластмасс, химических волокон, лаков и красок, медикаментов, технически и экономически доступны.

Однако высокая токсичность продуктов галогенорганического синтеза представляет непосредственную опасность для живых систем [1]. Известно, что хлорированные углеводороды являются основным загрязнителем грунтовых вод. Поэтому так актуальна проблема поиска новых путей утилизации и уничтожения отходов, содержащих галогенуглеводороды, которых, по данным [2], ежегодно накапливается порядка 1,5 млн тонн.

Реагентные методы, использующиеся для детоксикации почв, шламов и сточных вод, требуют дополнительных затрат сырья, характеризуются быстрым износом оборудования и образованием значительных количеств трудноутилизируемых вторичных отходов. Электрохимические и пиролитические методы сопряжены с высокими энергетическими затратами, расходом дорогостоящих специальных материалов и низкой избирательностью. В то же время электрохимические процессы не обеспечивают полной деградации опасных отходов, а ряд объектов для переработки 
пиролитическим методом сравнительно узок. Процессы биотрансформации достаточно широко используются при детоксикации водоемов, почв, а также промышленных и коммунальных сточных вод с низким содержанием хлорорганических загрязнителей. Основной недостаток этих методов - их низкая производительность, обусловленная высокой устойчивостью хлорорганических соединений.

Среди перспективных технологий защиты окружающей среды особое положение занимают окислительные процессы $[1,2,4,5]$ - сжигание в открытом пламени, каталитическое окисление на твердофазных катализаторах, глубокое окисление на расплавленных катализаторах [8]. При сжигании в открытом пламени при температурах выше $1200^{\circ} \mathrm{C}$ на стадии закаливания возможно образование еще более токсичных соединений класса диоксинов, дибензофуранов и оксидов азота [10].

Процессы гетерогенно-каталитического окисления отходов имеют ряд важных преимуществ перед методами огневого обезвреживания $[9,14]$. К таким преимуществам относятся: высокая степень деструкции перерабатываемых отходов, меньшие капитальные затраты и расход дополнительного топлива, возможность подавления образования высокотоксичных продуктов типа ПХДД и ПХДФ в отходящих газах [13], мягкие условия проведения процессов. Сравнительно низкие температуры процессов каталитического окисления галогенуглеводородов дают еще одно преимущество этому методу, заключающееся в отсутствии в продуктах окисления оксидов азота. Однако, несмотря на большое число исследований, направленных на разработку катализаторов гетерогенно-каталитического окисления хлорпроизводных, проблема создания катализатора, устойчивого к действию хлора и хлороводорода, далека от разрешения $[6,11,12,16]$.

Расплавы успешно применяются в качестве сред и катализаторов реакций глубокого окисления сложных смесей органических веществ, в том числе содержа- щих галогены $[8,11,15]$. Окисление проводят в интервале температур $350-900^{\circ} \mathrm{C}$ с высокой скоростью без образования пламени, что снижает вероятность образования $\mathrm{NO}_{x}$. Для проведения реакции требуется меньше тепла, чем при сжигании, что позволяет снизить расходы на топливо [9]. Устойчивость расплавленных систем к образующимся в процессе окисления отходов галогенам, коксу позволяет разделять и утилизировать сложные по химическому составу и агрегатному состоянию вещества.

Цель исследования - изучить глубокое окисление хлоруглеводородов ароматического ряда на примере модельного соединения - хлорбензола (ХБ) в расплавленных средах в зависимости от состава и природы активных компонентов, температуры. ХБ широко применяется как растворитель, является полупродуктом производства нитрохлорбензолов, аминов, нитрофенолов, хлоранилинов и др.

\section{Экспериментальная часть}

Превращение ХБ изучали на установке КЛ-1 (комплекс лабораторный для изучения катализаторов) в проточном реакторе из нержавеющей стали Х18Н10T. Общий рабочий объем реактора равен $1,3 \mathrm{~cm}^{3}$. Катализаторы в расплавленном виде наносили на внутреннюю трубку реактора в виде пленки. Парогазовую смесь получали в испарителе-сатураторе барботажного типа, входящем в комплект КЛ-1, при температуpe $25^{\circ} \mathrm{C}$. Скорость подачи парогазовой смеси контролировали с помощью блока подготовки газов. Отбор проб осуществляли с помощью двух 6-ходовых кранов дозаторов, размещенных до и после реактора.

Анализ исходной смеси и продуктов превращения ХБ проводили на двух последовательно соединенных хроматографах. ХБ определяли на аналитической колонке длиной 3 м, заполненной хроматоном $\mathrm{N}-\mathrm{AW}$ с 5\% неподвижной фазы QF-1 при температуре $130^{\circ} \mathrm{C}$. Анализ $\mathrm{CO}_{2}$ проводили на полисорбе-1 (длина колонки 3 м), а $\mathrm{O}_{2}$, $\mathrm{N}_{2}$, и $\mathrm{CO}$ разделяли на эрионите (длина колонки 3 м) при комнатной температуре. 
О превращении ХБ судили по изменению отношения $\mathrm{N}_{2}: \mathrm{O}_{2}$ и концентрации в отходящих газах.

\section{Результаты и обсуждение}

Установлено, что в условиях проведения эксперимента термическое превращение хлорбензола начинается при температуре $400^{\circ} \mathrm{C}$ и достигает конверсии равной $51,2 \%$ при $550^{\circ} \mathrm{C} \quad$ (табл. 1). Процесс сопровождается образованием большого количества кокса, что в конечном итоге приводит к нарушению циркуляции газовой смеси при температуре $600^{\circ} \mathrm{C}$. Соотношение $\mathrm{N}_{2}: \mathrm{O}_{2}$ возрастает при этом с 4,00 для исходной смеси до 27,41.

Таблииа 1

Термическое разложение ХБ

\begin{tabular}{|c|c|c|c|c|}
\hline $\begin{array}{l}\text { № } \\
\Pi / \Pi\end{array}$ & $\begin{array}{c}\mathrm{O}_{2}: \mathrm{C}_{6} \mathrm{H}_{5} \mathrm{Cl} \\
\text { от } \\
\text { стехиометрии }\end{array}$ & $\mathrm{N}_{2}: \mathrm{O}_{2}$ & $\begin{array}{c}\mathrm{CO}_{2} \\
\text { об. } \\
\%\end{array}$ & $\begin{array}{c}\text { Конверсия } \\
\mathrm{C}_{6} \mathrm{H}_{5} \mathrm{Cl}, \%\end{array}$ \\
\hline 130 & \multirow{9}{*}{2,5} & 3,86 & 0,0 & 0,00 \\
\hline 200 & & 3,86 & 0,0 & 0,00 \\
\hline 250 & & 3,90 & 0,0 & 0,00 \\
\hline 300 & & 3,92 & 0,0 & 0,00 \\
\hline 350 & & 3,86 & 0,0 & 0,00 \\
\hline 400 & & 3,95 & 0,0 & 4,90 \\
\hline 450 & & 4,06 & 0,0 & 6,50 \\
\hline 500 & & 4,30 & 1,2 & 15,40 \\
\hline 550 & & 7,27 & 2,4 & 51,20 \\
\hline
\end{tabular}

Анализ литературных данных показывает, что реакции каталитического окисления хлорароматических соединений протекают в несколько стадий с образованием различных промежуточных и конечных соединений. На протекание реакции по тому или иному механизму влияют условия проведения (температура, давление), состав катализатора, структура окисляемого субстрата. Механизм каталитического окисления хлорароматических соединений на примере хлорбензола, дихлорбензола на поверхности оксидного ванадиевого катализатора изучали в работе [6].

Окисление ХБ проводили в расплавленных системах на основе $\mathbf{N a}_{2} \mathbf{C O}_{3}-$ $-\mathbf{K}_{2} \mathbf{C O}_{3}$ (эвт.): $\mathrm{Na}_{2} \mathrm{CO}_{3}-\mathrm{K}_{2} \mathrm{CO}_{3}$ (эвт.) (I), $\mathrm{Na}_{2} \mathrm{CO}_{3}-\mathrm{K}_{2} \mathrm{CO}_{3}$ (эвт.) +20 мас.\% $\mathrm{V}_{2} \mathrm{O}_{5}$ (II), $\mathrm{Na}_{2} \mathrm{CO}_{3}-{ }_{2} \mathrm{CO}_{3}$ (эвт.) + 20 мас.\% $\% \mathrm{Sb}_{2} \mathrm{O}_{5}$ (III), NaOH-KOH (эвт.): $\mathrm{NaOH}-\mathrm{OH}$ (эвт.)(IV), $\mathrm{NaOH}-\mathrm{KOH}$ (эвт.) + 10 мас.\% $\mathrm{V}_{2} \mathrm{O}_{5}(\mathbf{V})$,
$\mathrm{NaCl}-\mathrm{CaCl}_{2}$ (эвт.) +10 мас.\% $\mathrm{V}_{2} \mathrm{O}_{5}$ (VI) и $\mathbf{N a C l}-\mathrm{CaCl}_{2}$ (эвт.): $\mathrm{NaCl}-\mathrm{CaCl}_{2}$ (эвт.) + +10 мас. $\% \mathrm{~V}_{2} \mathrm{O}_{5}$ (VII), $\mathrm{NaCl}-\mathrm{CaCl}_{2}$ (эвт.) + +20 мас. $\% \mathrm{~V}_{2} \mathrm{O}_{5}$ (VIII).

\section{$\mathrm{Na}_{2} \mathrm{CO}_{3}-\mathrm{K}_{2} \mathrm{CO}_{3}$ (эвт.)}

В результате глубокого окисления ХБ образуются $\mathrm{CO}_{2}, \mathrm{H}_{2} \mathrm{O}, \mathrm{HCl}, \mathrm{Cl}_{2}$. Ha pacплаве (I) степень превращения ХБ не достигает $100 \%$ (опыт 3-7 табл. 2).

Концентрация $\mathrm{CO}_{2}$ в отходящих газах ниже теоретически рассчитанной (7,0 об.\%), по-видимому, $\mathrm{CO}_{2}$ поглощается расплавом. Отношение $\mathrm{N}_{2}: \mathrm{O}_{2}$ в отходящих газах в процессе окисления ХБ изменяется в пределах 4,63-13,06 (п. п. 3-14 табл. 2), проходя через максимум. Теоретически рассчитанное отношение $\mathrm{N}_{2}: \mathrm{O}_{2}$ в отходящих газах при условии полного превращения ХБ равно 9,63. После прекращения подачи ХБ в реактор отношение $\mathrm{N}_{2}: \mathrm{O}_{2}$ приближается к 3,73 - воздух (п. п. 15-16 табл. 2).

В процессе глубокого окисления ХБ образуются $\mathrm{HCl}$ и (или) $\mathrm{Cl}_{2}$, которые взаимодействуют с компонентами расплава с образованием высокоплавких хлоридов металлов. В результате повы-

Таблица 2

\begin{tabular}{|c|c|c|c|c|}
\hline \multicolumn{5}{|c|}{$\begin{array}{c}\text { Окисление ХБ на расплаве } \\
\mathrm{Na}_{2} \mathrm{CO}_{3}-\mathrm{K}_{2} \mathrm{CO}_{3} \text { (эвт.) (I), } \\
\text { барботаж воздуха } 3 \text { л/ч, } \\
\text { расход по ХБ 0,2 г/ч, } 750 \text { ०C }\end{array}$} \\
\hline $\begin{array}{l}\text { № } \\
\text { ח/ח }\end{array}$ & $\begin{array}{c}\mathrm{O}_{2}: \mathrm{C}_{6} \mathrm{H}_{5} \mathrm{Cl} \\
\text { от } \\
\text { стехиометрии }\end{array}$ & $\mathrm{N}_{2}: \mathrm{O}_{2}$ & $\begin{array}{l}\mathrm{CO}_{2}, \\
\text { об. } \\
\%\end{array}$ & $\begin{array}{c}\text { Конверсия } \\
\mathrm{C}_{6} \mathrm{H}_{5} \mathrm{Cl}, \%\end{array}$ \\
\hline 1 & - & 3,77 & - & - \\
\hline 2 & - & 3,78 & - & - \\
\hline 3 & \multirow{12}{*}{2,5} & 4,63 & 0,90 & 99,90 \\
\hline 4 & & 8,22 & 2,10 & 99,93 \\
\hline 5 & & 6,58 & 0,60 & 99,95 \\
\hline 6 & & 7,25 & 1,10 & 99,95 \\
\hline 7 & & 5,81 & 0,80 & 99,91 \\
\hline 8 & & 6,94 & 2,60 & 100,00 \\
\hline 9 & & 8,87 & 3,40 & 100,00 \\
\hline 10 & & 10,08 & 3,80 & 100,00 \\
\hline 11 & & 13,06 & 2,60 & 100,00 \\
\hline 12 & & 7,46 & 2,90 & 100,00 \\
\hline 13 & & 8,14 & 2,80 & 100,00 \\
\hline 14 & & 7,98 & 2,70 & 100,00 \\
\hline 15 & - & 6,26 & 2,30 & - \\
\hline 16 & - & 4,23 & 0,70 & - \\
\hline 17 & - & 3,99 & 0,40 & - \\
\hline
\end{tabular}


шается температура плавления и снижается каталитическая активность системы. Ранее показано [3], что в присутствии оксидов переходных металлов (например $\mathrm{V}_{2} \mathrm{O}_{5}$ ) хлорид-ионы окисляются с образованием молекулярного хлора, что продлевает срок службы расплава.

При добавлении к смеси (I) 20 мас.\% пентаоксида ванадия в отходящих газах присутствует $\mathrm{CO}_{2}$ даже в случае барботирования через реактор воздуха, не содержащего паров ХБ за счет взаимодействия $\mathrm{V}_{2} \mathrm{O}_{5}$ с карбонатами натрия и калия.

Конверсия ХБ на расплаве (II) достигает 100\%. Концентрация $\mathrm{CO}_{2}$ в отходящих газах также ниже теоретической вследствие поглощения $\mathrm{CO}_{2}$ расплавом. При повышении нагрузки по ХБ на катализатор с 0,2 г/ч до 0,25 г/ч (стехиометрическое соотношение $\mathrm{O}_{2}:$ ХБ соответственно 2,5 и 1,9$)$ концентрация $\mathrm{CO}_{2}$ возрастает в 1,5 раза (п. п. 3 - 9 и 16 - 23 табл. 3 ),

\section{Окисление ХБ на расплаве}

Таблица 3

$\mathrm{Na}_{2} \mathrm{CO}_{3}-\mathrm{K}_{2} \mathrm{CO}_{3}$ (эвт.) + 20 мас. $\% \mathrm{~V}_{2} \mathrm{O}_{5}$ (II), барботаж воздуха 3 л/ч, 750 ० $\mathrm{C}$

\begin{tabular}{|c|c|c|c|c|}
\hline $\begin{array}{l}\text { № } \\
\Pi / \Pi\end{array}$ & $\begin{array}{c}\mathrm{O}_{2}: \mathrm{C}_{6} \mathrm{H}_{5} \mathrm{Cl} \\
\text { от } \\
\text { стехиометрии }\end{array}$ & $\mathrm{N}_{2}: \mathrm{O}_{2}$ & $\begin{array}{c}\mathrm{CO}_{2}, \\
\text { oб. } \\
\%\end{array}$ & $\begin{array}{c}\text { Конверсия } \\
\mathrm{C}_{6} \mathrm{H}_{5} \mathrm{Cl}, \%\end{array}$ \\
\hline 1 & & 4,27 & 0,47 & - \\
\hline 2 & - & 4,15 & 0,71 & - \\
\hline 3 & \multirow{7}{*}{2,5} & 4,43 & 0,76 & 100,00 \\
\hline 4 & & 9,64 & 1,75 & 100,00 \\
\hline 5 & & 10,28 & 1,76 & 100,00 \\
\hline 6 & & 10,75 & 1,85 & 100,00 \\
\hline 7 & & 10,05 & 1,78 & 100,00 \\
\hline 8 & & 10,47 & 1,90 & 100,00 \\
\hline 9 & & 8,63 & 1,05 & 100,00 \\
\hline 10 & - & 4,52 & 0,62 & - \\
\hline 11 & - & 5,00 & 0,00 & - \\
\hline 12 & - & 3,77 & - & - \\
\hline 13 & \multirow{11}{*}{$1,9^{*}$} & 5,21 & 0,90 & 100,00 \\
\hline 14 & & 5,95 & 1,14 & 100,00 \\
\hline 15 & & 7,73 & 0,90 & 100,00 \\
\hline 16 & & 17,92 & 2,14 & 100,00 \\
\hline 17 & & 36,35 & 2,52 & 100,00 \\
\hline 18 & & 32,41 & 2,47 & 100,00 \\
\hline 19 & & 32,29 & 2,51 & 100,00 \\
\hline 20 & & 25,73 & 2,56 & 100,00 \\
\hline 21 & & 11,52 & 2,06 & 100,00 \\
\hline 22 & & 9,03 & 2,09 & 100,00 \\
\hline 23 & & 11,63 & 2,23 & 100,00 \\
\hline
\end{tabular}

увеличивается отношение азота к кислороду - с 10 до 30 (теоретические значения $\mathrm{N}_{2}: \mathrm{O}_{2}$ соответственно равны 6,16 и 8,33 ). Параллельно с процессом деструкции ХБ протекают реакции окисления-восстановления ионов ванадия. После 15 часов работы отмечено повышение температуры плавления системы (II). Методом капиллярного электрофореза обнаружено, что в системе после окисления ХБ содержится 1 мас.\% хлорид-ионов (теоретически рассчитанное).

На катализаторе (III) наблюдается полное превращение ХБ (табл. 4) . Отношение $\mathrm{N}_{2}: \mathrm{O}_{2}$ в отходящих газах при 3-кратном избытке $\mathrm{O}_{2}$ по отношению к ХБ превышает рассчитанное $(5,17)$. Возможно, кислород не только расходуется на окисление ХБ, но и взаимодействует с оксидом сурьмы (восстановление Sb (III) до Sb (V)).

При температуре $750^{\circ} \mathrm{C}$ хлорбензол частично подвергается термическому распаду (наряду с глубоким окислением). Продукты разложения окислились в расплаве и на выходе из реактора обнаружены не были.

Таким образом, из рассмотренных систем наиболее эффективной в процессе окисления ХБ является смесь карбонатов натрия и калия с добавкой 20 \% пентаоксида ванадия (система II).

\section{NaOH-KOH (эвT.)}

Каталитическую активность гидроксиды натрия и калия проявляют вследствие

Таблища 4

Окисление ХБ на расплаве $\mathrm{Na}_{2} \mathrm{CO}_{3}-\mathrm{K}_{2} \mathrm{CO}_{3}$ (эвт.)

+ 20 мас. \% $\mathrm{Sb}_{2} \mathrm{O}_{5}$ (III), барботаж воздуха 3 л/ч, расход по ХБ 0,14 г/4, 750 ० $\mathrm{C}$

\begin{tabular}{|c|c|c|c|c|}
\hline $\begin{array}{c}\text { № } \\
\mathbf{n} / \mathbf{n}\end{array}$ & $\begin{array}{c}\mathbf{O}_{2}: \mathbf{C}_{6} \mathrm{H}_{5} \mathrm{Cl} \\
\text { от } \\
\text { стехиометрии }\end{array}$ & $\mathrm{N}_{2}: \mathbf{O}_{2}$ & $\begin{array}{c}\mathbf{C O}_{2}, \\
\text { об. } \\
\%\end{array}$ & $\begin{array}{c}\text { Конверсия } \\
\mathbf{C}_{6} \mathrm{H}_{5} \mathrm{Cl}, \%\end{array}$ \\
\hline 1 & - & 3,99 & - & - \\
\hline 2 & - & 4,39 & - & - \\
\hline 3 & & 4,04 & - & 100,00 \\
\hline 4 & & 9,11 & 1,28 & 100,00 \\
\hline 5 & \multirow{2}{*}{3,4} & 10,19 & 2,18 & 100,00 \\
\hline 6 & & 12,60 & 2,21 & 100,00 \\
\hline 7 & & 11,74 & 2,47 & 100,00 \\
\hline 8 & & 10,72 & 2,61 & 100,00 \\
\hline 9 & - & 5,05 & 0,76 & - \\
\hline 10 & - & 4,29 & 0,19 & - \\
\hline
\end{tabular}


наличия пероксидов и супероксидов натрия и калия. Использование данной системы в качестве катализатора позволяет проводить процесс окисления при достаточно низких температурах $\left(\mathrm{T}_{\text {пл }}=170^{\circ} \mathrm{C}\right)$. При действии щелочей происходит замещение атома хлора в молекуле ХБ на группу $\mathrm{OH}$, а образовавшийся фенол подвергается окислению. Окисление ХБ проводили в интервале температур $130-500^{\circ} \mathrm{C}$. Мольное отношение $\mathrm{O}_{2}$ :ХБ составляло 17,2 (по стехиометрии 7,0). Зависимость степени превращения ХБ на расплаве (IV) от температуры приведена в табл. 5. Превращение ХБ начинается при температуре $400^{\circ} \mathrm{C}$ и достигает величины $15,76 \%$ при $500^{\circ} \mathrm{C}$. Проведение процесса превращения при более высокой температуре было затруднительно, ввиду коксования. Сравнивая результаты окисления ХБ на расплаве (IV) и процесса термического разложения, можно предположить, что основным путем превращения хлорбензола в щелочном расплаве при температурах выше $500^{\circ} \mathrm{C}$ является термический распад. Об этом свидетельствуют практически одинаковые значения конверсии, а также значительное количество углерода (кокса) на барботажной трубке и стенках реактоpa. Выделяющиеся при окислении ХБ $\mathrm{HCl}$ и $\mathrm{Cl}_{2}$, взаимодействуют с расплавом с образованием хлоридов натрия и калия, что приводит к повышению температуры плавления системы и ее вязкости.

Таблица 5

\begin{tabular}{|c|c|c|c|c|}
\hline \multicolumn{5}{|c|}{$\begin{array}{c}\text { Окисление ХБ на расплаве } \\
\text { NaОН-КОН (эвт.) (IV), } \\
\text { барботаж воздуха } 3 \text { л/ч }\end{array}$} \\
\hline $\begin{array}{l}\text { T, } \\
\text { oC }\end{array}$ & $\begin{array}{c}\mathrm{O}_{2}: \mathrm{C}_{6} \mathrm{H}_{5} \mathrm{Cl} \\
\text { от } \\
\text { стехиометрии }\end{array}$ & $\mathrm{N}_{2}: \mathrm{O}_{2}$ & $\begin{array}{l}\mathrm{CO}_{2}, \\
06 . \\
\%\end{array}$ & $\begin{array}{l}\text { Конверсия } \\
\left(\mathrm{C}_{6} \mathrm{H}_{5} \mathrm{Cl}\right), \%\end{array}$ \\
\hline 130 & \multirow{9}{*}{ rensur } & 4,18 & 0,00 & 0,00 \\
\hline 170 & & 4,13 & 0,00 & 0,00 \\
\hline 220 & & 4,19 & 0,00 & 0,00 \\
\hline 270 & & 3,84 & 0,00 & 0,00 \\
\hline 320 & & 3,73 & 0,00 & 0,00 \\
\hline 370 & & 3,83 & 0,00 & 1,77 \\
\hline 400 & & 3,87 & 0,00 & 2,32 \\
\hline 450 & & 4,05 & 1,56 & 5,00 \\
\hline 500 & & 4,60 & 3,12 & 15,76 \\
\hline
\end{tabular}

$\mathrm{V}_{2} \mathrm{O}_{5}$ способствует окислению ароматических углеводородов, интенсифицирует гетерообмен катализатора с кислородом и способствует увеличению срока службы катализатора за счет окисления хлорид-ионов до хлора. Процесс окисления ХБ в расплаве $(\mathbf{V})$ проводили в избытке по кислороду при мольном отношении $\mathrm{O}_{2}$ :ХБ, равном 17,2 (по стехиометрии 7) в интервале температур $130-700^{\circ} \mathrm{C}$. Окисление ХБ начинается при $450^{\circ} \mathrm{C}$ (конверсия равна 2,20\%) и достигает $100 \%$ при $700^{\circ} \mathrm{C}$ (табл. 6). Продуктами окисления являются $\mathrm{CO}_{2}, \mathrm{H}_{2} \mathrm{O}, \mathrm{HCl}, \mathrm{Cl}_{2}$. $\mathrm{CO}$ в отходящих газах обнаружен не был. Отложение кокса наблюдается в меньшей степени в сравнении с (IV). При температуре выше $650^{\circ} \mathrm{C}$ преобладает процесс термического разложения ХБ, о чем свидетельствует также высокое значение отношения $\mathrm{N}_{2}: \mathrm{O}_{2}$, которое при $700^{\circ} \mathrm{C}$ равно 41,32 .

\section{NaCl-CaCl 2 (эвт.)}

Окисление ХБ в расплавах (VII) и (VIII) проводили в интервале температур $200-600^{\circ} \mathrm{C}$. Мольное отношение $\mathrm{O}_{2}$ :ХБ в пределах 17,2 (по стехиометрии $7,0)$. Конверсия ХБ на катализаторе (VIII) в интервале температур $400-600^{\circ} \mathrm{C}$ выше, а соотношение $\mathrm{N}_{2}: \mathrm{O}_{2}(4,24)$ практически совпадает с соотношением для

Таблицу 6

\section{Окисление ХБ на расплаве}

$\mathrm{NaOH}-\mathrm{KOH}$ (эвт.) + 10 мас.\% $\mathrm{V}_{2} \mathrm{O}_{5}$ (IV), барботаж воздуха 3 л/4

\begin{tabular}{|c|c|c|c|c|}
\hline $\begin{array}{l}\mathrm{T}, \\
{ }^{\circ} \mathrm{C}\end{array}$ & $\begin{array}{c}\mathrm{O}_{2}: \mathrm{C}_{6} \mathrm{H}_{5} \mathrm{Cl} \\
\text { от } \\
\text { стехиометрии }\end{array}$ & $\mathrm{N}_{2}: \mathrm{O}_{2}$ & $\begin{array}{c}\mathrm{CO}_{2}, \\
\text { об. } \\
\%\end{array}$ & $\begin{array}{c}\text { Конверсия } \\
\left(\mathrm{C}_{6} \mathrm{H}_{5} \mathrm{Cl}\right), \\
\%\end{array}$ \\
\hline 130 & \multirow{13}{*}{2,5} & 3,80 & 0,00 & 0,00 \\
\hline 170 & & 3,89 & 0,00 & 0,00 \\
\hline 220 & & 3,90 & 0,00 & 0,00 \\
\hline 270 & & 3,92 & 0,00 & 0,00 \\
\hline 320 & & 4,03 & 0,00 & 0,00 \\
\hline 370 & & 4,03 & 0,29 & 0,00 \\
\hline 400 & & 4,00 & 1,88 & 0,00 \\
\hline 450 & & 4,30 & 2,33 & 2,20 \\
\hline 500 & & 4,15 & 1,18 & 15,56 \\
\hline 550 & & 4,37 & 2,20 & 27,78 \\
\hline 600 & & 5,52 & 4,21 & 49,49 \\
\hline 650 & & 14,26 & 9,09 & 82,81 \\
\hline 700 & & 41,32 & 4,47 & 100,00 \\
\hline
\end{tabular}


исходной смеси (табл. 7). В процессе термического разложения ХБ при $400^{\circ} \mathrm{C}$ и одинаковом мольном отношении $\mathrm{O}_{2}$ :ХБ превращается лишь 4,93\% ХБ по сравнению с 38,50\% на (VIII) и 8,15\% для системы (VII). Конверсия ХБ достигает значения $82,78 \%$ уже при $500^{\circ} \mathrm{C}$ $\left(\mathrm{N}_{2}: \mathrm{O}_{2}=5,05\right)$ на системе (VIII) в сравнении с $15,75 \%\left(\mathrm{~N}_{2}: \mathrm{O}_{2}=4,30\right)$ для катализатора с меньшим содержанием $\mathrm{V}_{2} \mathrm{O}_{5}$. На барботажной трубке и стенках реактора наблюдается отложение кокса.

\section{Таблича 7}

Окисление ХБ на расплавах $\mathrm{NaCl}-\mathrm{CaCl}_{2}$ (эвт.) + 10 мac.\% $\mathrm{V}_{2} \mathrm{O}_{5}$ (VII) и NaCl-CaCl (эвт.) + 20 мас.\% $\mathrm{V}_{2} \mathrm{O}_{5}$ (VIII), барботаж воздуха $3 \mathrm{л} / \mathbf{4}$

\begin{tabular}{|c|c|c|c|c|}
\hline $\begin{array}{l}\mathrm{T}, \\
{ }^{\circ} \mathrm{C}\end{array}$ & $\begin{array}{c}\mathrm{O}_{2}: \mathrm{C}_{6} \mathrm{H}_{5} \mathrm{Cl} \\
\text { от } \\
\text { стехиометрии }\end{array}$ & $\mathrm{N}_{2}: \mathrm{O}_{2}$ & $\begin{array}{l}\mathrm{CO}_{2}, \\
06 . \\
\%\end{array}$ & $\begin{array}{l}\text { Конверсия } \\
\left(\mathrm{C}_{6} \mathrm{H}_{5} \mathrm{Cl}\right), \%\end{array}$ \\
\hline 200 & \multirow{7}{*}{2,5} & 3,78 & 0,00 & 0,00 \\
\hline 300 & & 3,89 & 0,00 & 0,00 \\
\hline 400 & & 4,02 & 0,00 & 8,15 \\
\hline 450 & & 4,07 & 0,00 & 8,55 \\
\hline 500 & & 4,30 & 1,10 & 15,75 \\
\hline 550 & & 5,31 & 4,94 & 54,42 \\
\hline 600 & & 16,02 & 10,47 & 100,00 \\
\hline \multicolumn{5}{|c|}{ Окисление ХБ на расплаве (VIII) } \\
\hline 200 & \multirow{5}{*}{2,5} & 3,89 & 0,00 & 0,00 \\
\hline 300 & & 3,92 & 0,00 & 0,00 \\
\hline 400 & & 4,24 & 0,58 & 38,50 \\
\hline 450 & & 5,20 & 0,80 & 44,95 \\
\hline 500 & & 5,05 & 1,46 & 82,78 \\
\hline
\end{tabular}

Значение конверсии ХБ, равное $100 \%$ на катализаторе (VII), наблюдалось при $600^{\circ} \mathrm{C}$ (табл. 7). Окисление ХБ сопровождается значительным коксообразованием. Высокая степень конверсии уже при $400^{\circ} \mathrm{C}$ наблюдается на катализаторе (VIII), увеличивается с ростом температуры, мольного отношения $\mathrm{O}_{2}$ :ХБ.

На рисунке представлены зависимости конверсии ХБ от температуры для каталитических систем (IV)-(VIII).

Таким образом, на основании проведенных исследований можно сделать следующие выводы. Процесс термического распада ХБ в атмосфере воздуха при высоких температурах $\left(>500^{\circ} \mathrm{C}\right)$ сопровождается значительным коксообразованием, что затрудняет его использование.

Применение расплавов в реакциях глубокого окисления хлорорганических веществ имеет ряд преимуществ. Степень окисления ХБ на системах, содержащих карбонаты, гидроксиды, хлориды щелочных и щелочно-земельных металлов в присутствии оксидов переходных металлов выше. Высокая степень конверсии уже при $400^{\circ} \mathrm{C}$ наблюдается на катализаторе $\mathrm{NaCl}-\mathrm{CaCl}_{2} \quad$ (эвт.)+20 мас.\% $\quad \mathrm{V}_{2} \mathrm{O}_{5}$ (VIII). И увеличивается с ростом температуры, мольного отношения $\mathrm{O}_{2}$ :ХБ. Процесс коксообразования в меньшей степе-

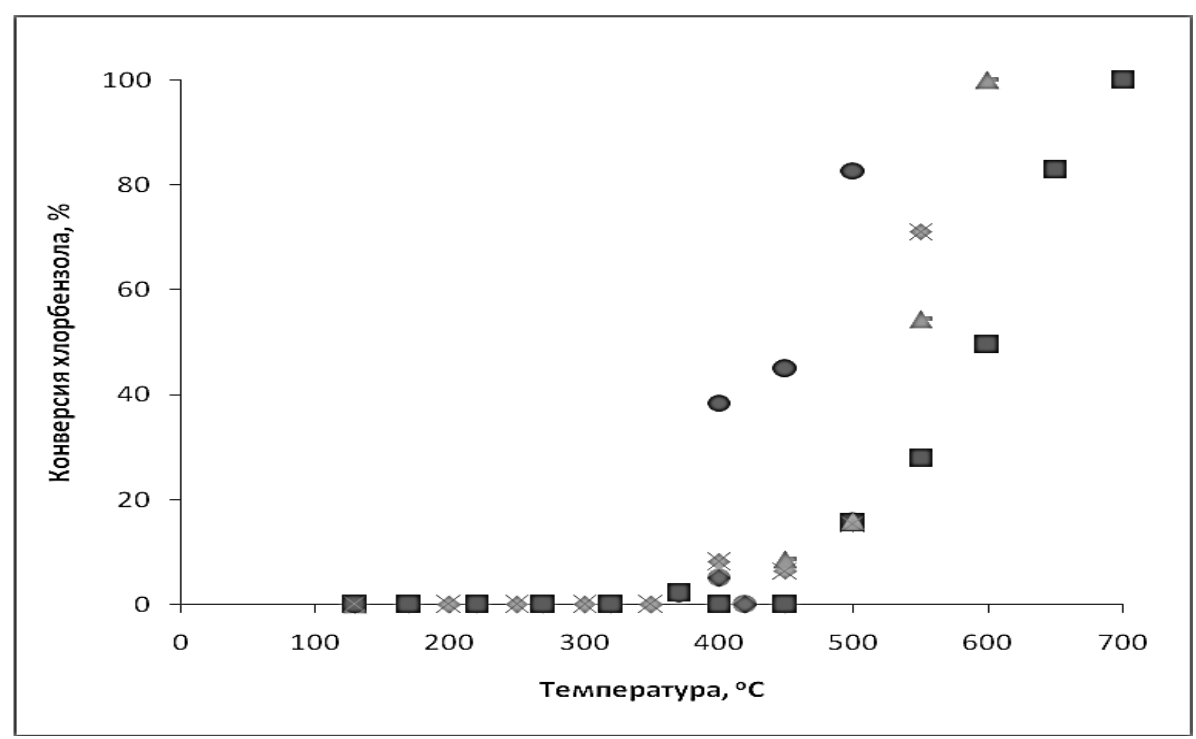

Рис. Зависимость конверсии хлорбензола от температуры:× - термическое разложение, $-\mathrm{NaOH}-\mathrm{KOH}$ (эвт.), - - $\mathrm{NaOH}-\mathrm{KOH}$ (эвm.) + 10 мac.\% $\mathrm{V}_{2} \mathrm{O}_{5}$,

$\boldsymbol{\Delta}-\mathrm{NaCl}_{-} \mathrm{CaCl}_{2}$ (эвт.) $+10 \mathrm{Mac}_{\%} \% \mathrm{~V}_{2} \mathrm{O}_{5}, \bullet-\mathrm{NaCl}_{-} \mathrm{CaCl}_{2}$ (эвт.) $+20 \mathrm{Mac} \% \mathrm{~V}_{2} \mathrm{O}_{5}$ 
ни наблюдается для каталитической системы $\mathrm{NaOH}-\mathrm{KOH}++10$ мас.\% $\mathrm{V}_{2} \mathrm{O}_{5}$ (эвт.) (VI). Образующиеся при окислении хлорароматических соединений хлорид-ионы под действием оксидов переходных металлов окисляются с образованием молекулярного хлора, что продлевает срок службы данных каталитических систем.
Изученные системы могут изменять свой состав в результате изменения состава и парциального давления газообразных продуктов над расплавом, что наблюдается в процессе окисления хлоруглеводородов, в результате чего образуются системы, содержащие гидроксиды, карбонаты, хлориды и ванадаты натрия и калия.

\section{Библиографический список}

1. Занавескин Л.Н., Аверьянов В.А. Полихлорбифенилы: проблемы загрязнения окружающей среды и технологические методы обезвреживания // Успехи химии. - 1998. - Т. 67. - № 8. - С. 788-800.

2. Занавескин Л.Н., Конорев О.А., Аверьянов В.А. Окислительные методы переработки и детоксикации хлорорганических отходов. Курс на ресурсосбережение и экологическую безопасность // Химическая промышленность. - 2002. - №2. - С. 3-18.

3. Взаимодействия в системе хлорид натрия-пентаоксид ванадия / T.A. Роздяловская [и др.] // Расплавы. - 2004. - №4. - С. 75-84.

4. Исмагилов 3.Р., Керженцеев М.А. Катализаторы и процессы каталитического горения // Химическая промышленность. - 1996. - №3. - С.53-59.

5. Савельев А.Н. Методы утилизации хлорорганических отходов и их экономическая оценка // Химическая промышленность. - 2006. - Т. 83. - №2. - С. 73-82.

6. Формы адсорбции бензола и его хлорпроизводных на поверхности оксидного ванадиевого катализатора / И.В. Давиденко, А.А. Давыдов, Ю.И Пятнииякий. и др. // Журнал физической химии. 1991. - Т. 65. - № 1. - С. 164-168.

7. Чекрышкин Ю.С., Роздяловская Т.А., Федоров А.А., Лисичкин Г.В. Окислительный катализ на высокотемпературных ионных расплавах // Успехи химии. - 2007. - Т. 76. - № 2. - С. 169-186.

8. Чекрышкин Ю.С., Роздяловская Т.А., Федоров А.А. Гетерогенно-каталитическое глубокое окисление галогенсодержащих органических веществ на расплавах электролитов. - Екатеринбург: УрО РАН, 2005. $-124 \mathrm{c}$.

9. Abating halogenated VOCs / R.A. Keller, J.A. Dyer // Chemical Engineering - 1998. - Vol. 105. - №1. P. 100-105.

10. An experimental and numerical study of the thermal oxidation of chlorobenzene / B. Higgins [et. al.]// Chemosphere. 2001. Vol. 42. P. 703-717.

11. Destruction of chlorinated organic solvents in a two-stage molten salt oxidation reactor system / Yang Hee-Chul, Eun Hee-Chul, Kim Eung-Ho, Cho Yong-June // Chemical Engineering Science. - 2007. Vol. 62. - № 18-20. - P. 5137-5143.

12. Jones J., Ross J.R.H. The development of supported vanadia catalysts for the combined catalytic removal of the oxides of nitrogen and of chlorinated hydrocarbons from flue gases // Catalysis Today. 1997. - Vol. 35. - P. 97-105.

13. Lago R.M., Green M.L.H., Tsang S.C., Odlyha M. Catalytic decomposition of chlorinated organics in air by copper chloride based catalysts // Applied Catalysis B: Enviromental. - 1996. - Vol. 8. - Issue 1. P. 107-121.

14. Lasar L., Balasanian I., Bandrabur F. Conversion of the chlorinated aromatic derivatives on metallic oxides catalysts // Actes du 3 Colloque franco-roumain de chimie appliquee (COFrRoCA - 2004) Bacau. - 2004. - P. 428-431.

15. Oxidation of dichloromethane over Pt, Pd, Rh, and V2O5 catalysts supported on Al2O3, Al2O3-TiO2 and Al2O3-CeO2 / S. Pitkäaho [et. al.] // Applied Catalysis B: Environmental. 2013. Vol. 138-139. P. 33-42.

16. Oxidation of perchloroethylene-Activity and selectivity of $\mathrm{Pt}, \mathrm{Pd}, \mathrm{Rh}$, and V2O5 catalysts supported on A12O3, Al2O3-TiO2 and Al2O3-CeO2 / S. Pitkäaho [et. al.] // Applied Catalysis B: Environmental. 2012. Vol. 113-114. P. 150-159. 


\title{
OXIDATION OF CHLOROAROMATIC COMPOUNDS (ON THE EXAMPLE OF CHLOROBENZENE) IN MOLTEN SALTS
}

\author{
T.A. Rozdyalovskaya \\ Institute of Technical Chemistry UB RAS
}

The article studies the reaction of deep oxidation of chlorobenzene in molten mixtures of hydroxides, carbonates and chlorides of alkali and alkaline earth metals with and without active components $\mathrm{V}_{2} \mathrm{O}_{5}$ and $\mathrm{Sb}_{2} \mathrm{O}_{5}$ depending on the temperature, catalyst loading and the molar ratio of oxidant gas (air mixture) to chlorobenzene. Thermal decomposition of chlorobenzene proceeds with a low degree of conversion accompanied by the significant coke formation. The research has shown that among the studied catalytic systems molten catalysts based on eutectic mixture of sodium and calcium chlorides with content of $20 \mathrm{wt} . \% \mathrm{~V}_{2} \mathrm{O}_{5}$ demonstrate the highest activity in the deep oxidation of chlorobenzene. The process of coke formation is less observed for the catalytic system $\mathrm{NaOH}-\mathrm{KOH}+10 \mathrm{wt} . \% \mathrm{~V}_{2} \mathrm{O}_{5}$ (euth.). The chloride ions formed during the oxidation of chloroaromatic compounds under the action of transition metal oxides are oxidized to form molecular chlorine stretching service time of the catalytic systems.

Keywords: deep oxidation, waste destruction, chlorobenzene, molten catalysts, transition metal oxides.

\section{Сведения об авторе}

Роздяловская Татьяна Александровна, кандидат химических наук, старший научный сотрудник, Институт технической химии УрО РАН - филиал Пермского федерального исследовательского центра УрО РАН (ИТХ УрО РАН), 614013, ул. Академика Королева, 3; e-mail: rozdta@mail.ru 